\title{
O PREPARO DA EQUIPE CIRÚRGICA: ASPECTO RELEVANTE NO CONTROLE DA CONTAMINAÇÃO AMBIENTAL
}

\author{
Caroline Cataneo ${ }^{1}$ \\ Cristiane Aparecida Silveira ${ }^{1}$ \\ Erica Simpionato ${ }^{1}$ \\ Fernanda Carolina Camargo ${ }^{1}$ \\ Flavia Alline de Queiroz ${ }^{1}$ \\ Marilise Carrascoza Cagnin ${ }^{1}$
}

Cataneo C, Silveira CA, Simpionato E, Camargo FC, Queiroz FA, Cagnin MC. O preparo da equipe cirúrgica: aspecto relevante no controle da contaminação ambiental. Rev Latino-am Enfermagem 2004 março-abril; 12(2):283-6.

O controle da contaminação ambiental tem sido considerado como medida racional para a prevenção da infecção do sítio cirúrgico. O objetivo deste estudo é apresentar as atuais recomendações relacionadas ao preparo da equipe cirúrgica e tecer considerações sobre o papel do enfermeiro no controle da contaminação ambiental. Baseados na literatura atual, abordamos pontos relacionados à paramentação cirúrgica e a escovação das mãos. Os estudos apontam que o preparo da equipe cirúrgica constitui barreira de proteção importante para a prevenção da infecção do sítio cirúrgico; entretanto salientam a necessidade dos profissionais de saúde realizarem os procedimentos de forma adequada.

DESCRITORES: salas de cirurgia; infecção hospitalar; enfermagem

\section{THE PREPARATION OF THE SURGICAL TEAM: SIGNIFICANT ASPECT IN} THE CONTROL OF ENVIRONMENTAL CONTAMINATION

The control of environmental contamination has been considered a rational measure for preventing surgical site infection. This study aims to present the current recommendations related to the preparation of the surgical team and to discuss the role of nurses in controlling environmental contamination. On the basis of current literature, we treat issues related to surgical garment and hand brushing. Studies indicate that the preparation of the surgical team constitutes an important protection barrier for preventing surgical site infection; nevertheless, the need is highlighted for health professionals to realize procedures adequately.

DESCRIPTORS: operating rooms; cross infection; nursing

\section{LA PREPARACIÓN DEL EQUIPO QUIRÚRGICO: ASPECTO RELEVANTE EN EL CONTROL DE LA CONTAMINACIÓN AMBIENTAL}

El control de la contaminación ambiental ha sido considerado como una medida racional para la prevención de la infección en el sitio quirúrgico. El objetivo de este estudio es presentar las recomendaciones actuales con respecto a la preparación del equipo quirúrgico y hacer consideraciones acerca del papel del enfermero en el control de la contaminación ambiental. Basados en la literatura actual, tratamos puntos relacionados con el vestuario quirúrgico y al cepillado de las manos. Estudios indican que la preparación del equipo quirúrgico sirve como una importante barrera de protección en la prevención de la infección en el sitio quirúrgico; sin embargo, destacan que los profesionales de salud necesitan realizar los procedimientos de manera adecuada.

DESCRIPTORES: quirófanos; infección hospitalaria; enfermería

\footnotetext{
${ }^{1}$ Acadêmicos do 8oㅗ semestre de graduação, e-mail: casilve@yahoo.com.br; Orientador: Prof ${ }^{\underline{a}}$ Dr ${ }^{\underline{a}}$ Cristina Maria Galvão, Professor Associado, e-mail: crisgalv@eerp.usp.br. Escola de Enfermagem de Ribeirão Preto, da Universidade de São Paulo, Centro Colaborador da OMS para o desenvolvimento da pesquisa em enfermagem
} 
$\boldsymbol{A}$ infecção hospitalar constitui um dos grandes problemas enfrentados pelos profissionais de saúde e pacientes, ressaltamos aqui a infecção do sítio cirúrgico (ISC). Estima-se, no Brasil, que a ISC ocorra após 11\% das operações ${ }^{(1)}$. Os estudiosos reconhecem que a maioria das infecções hospitalares, inclusive a da ferida cirúrgica, é de origem endógena (70 a 80\%). A segunda causa da transmissão da ISC é a equipe cirúrgica, caracterizada pela infecção veiculada principalmente pelas vias aéreas superiores e pelas mãos. Outros mecanismos de contaminação são os artigos médico-hospitalares e o ar ambiente ${ }^{(2)}$.

O controle da contaminação ambiental no centro cirúrgico (CC) tem sido considerado como medida racional pelo Centers for Disease Control and Prevention (CDC) para a prevenção da $\operatorname{ISC}^{(3)}$. Esse controle assume conotação mais ampla e não se limita somente à limpeza de pisos, paredes e equipamentos; englobando também o controle do acesso e do trânsito de pessoas dentro da sala de operação durante a cirurgia, movimentação das portas, sistema de ventilação e paramentação adequada da equipe cirúrgica ${ }^{(4)}$.

O presente estudo tem como objetivos apresentar as atuais recomendações relacionadas ao preparo da equipe cirúrgica e tecer considerações sobre o papel do enfermeiro no controle da contaminação ambiental.

\section{O PREPARO DA EQUIPE CIRÚRGICA}

Sabe-se que a infecção do sítio cirúrgico é multifatorial, sendo a equipe cirúrgica uma importante fonte de patógenos para sua etiologia. Frente a isso "o uso da paramentação é uma forma coerente de prevenção de transmissão de contaminação e de infecção, tanto para o profissional como para o paciente, e o uso adequado está relacionado, também, com a garantia da manutenção da

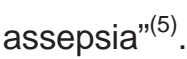

A seguir, descrevemos os principais pontos relacionados ao preparo da equipe cirúrgica, baseados na literatura atual.
O uso da paramentação cirúrgica tem como finalidade original "a formação de uma barreira microbiológica contra penetração de microorganismos no sítio cirúrgico do paciente, oriundos dele mesmo, dos profissionais, materiais, equipamentos e ar ambiente"(6). Os componentes da paramentação cirúrgica são:

- aventais: diariamente inúmeras células epiteliais despreendem-se da pele, sendo que muitas delas levam consigo bactérias. A utilização do avental objetiva reduzir a dispersão das bactérias no ar (aproximadamente 30\%) e evitar o contato da pele da equipe com sangue e fluidos corporais que possam contaminar a roupa privativa. O CDC recomenda troca de avental quando estiver visivelmente sujo com sangue ou outro fluido corporal potencialmente infectante ${ }^{(1)}$;

- luvas: são utilizadas pelos membros da equipe cirúrgica com a função de proteger o paciente das mãos desses e proteger a equipe de fluidos potencialmente contaminados. Com a finalidade de reduzir e prevenir o risco de exposição ao sangue, recomenda-se o uso do duplo enluvamento do cirurgião e primeiro assistente para qualquer procedimento que durar mais que uma hora, pois estudos demonstraram que o procedimento de longa duração influencia a taxa de furos nas luvas e aumenta a exposição ao sangue ${ }^{(1)}$; - máscaras: o uso justifica-se por dois aspectos: proteger o paciente da contaminação (principalmente quando a incisão cirúrgica está aberta) de microorganismos, oriundos do nariz e da boca dos profissionais, liberados no ambiente, quando eles falam, tossem e respiram, protege a mucosa dos profissionais de respingos de secreções provenientes dos pacientes durante 0 procedimento cirúrgico ${ }^{(5)}$. Esta via de transmissão é considerada infreqüente porque nem todas as partículas expelidas contêm bactérias, sendo sua utilização mais eficiente para a equipe de saúde por existir o risco de exposição a fluidos infectantes. A Occupational Safety and Health Administration (OSHA) exige a utilização de máscaras que protejam totalmente a boca e o nariz, combinadas com protetores oculares, e a Association of Perioperative Registered Nurses (AORN) recomenda que todas as pessoas devem utilizar máscaras cirúrgicas ao entrarem na sala de operação, quando materiais e 
equipamentos estéreis estiverem abertos. Elas devem ser descartadas após cada uso, manipulando-se somente as tiras, serem trocadas quando estiverem molhadas, não devendo ficar penduradas no pescoço e nem dobradas dentro do bolso para serem utilizadas posteriormente ${ }^{(1)}$; - propés: o uso é atualmente uma questão polêmica, uma vez que ainda se fazem necessários estudos criteriosos para que essa prática seja abolida ${ }^{(3)}$. Consiste em procedimento mais significante para proteger a equipe à exposição de sangue, fluidos corporais e materiais pérfurocortantes do que medida de proteção ao paciente. A supervisão deve ser constante quanto ao uso indiscriminado e incorreto dos propés, como substituí-los pelos sapatos $^{(1)}$. Para garantir maior proteção eles devem ser calçados com sapatos fechados;

- gorros: o CDC recomenda sua utilização com intuito de evitar a contaminação do sítio cirúrgico por cabelo ou microbiota presente nele, o gorro deve ser bem adaptado, permitindo cobrir totalmente o cabelo na cabeça e face ${ }^{(1)}$.

Ressaltamos, ainda, que, devido às doenças transmissíveis por substâncias orgânicas dos pacientes (por exemplo, a Aids e a hepatite B), adicionou-se o uso de óculos ou máscaras protetoras dos olhos como componentes da paramentação cirúrgica ${ }^{(6)}$.

\section{ESCOVAÇÃO DAS MÃOS}

"É um processo que visa a retirada de sujeira e detritos, redução substancial ou eliminação da flora transitória e redução parcial da flora residente, uma vez que a eliminação dessa última é virtualmente impossível”(1). Inicialmente é necessário a retirada de jóias e acessórios da região das mãos, punhos e antebraços. A torneira deve ser acionada por pé ou cotovelo e não manualmente; as mãos e antebraços são molhados com água corrente. A solução antisséptica preconizada (PVPI degermante ou clorehexidina) deve ser aplicada sobre a palma das mãos, iniciando pelas extremidades dos dedos com especial atenção sobre os leitos subungueais e espaços interdigitais (escovação), o processo deve continuar pelas faces das mãos e antebraços (fricção). O enxágüe deve ser executado com água corrente a partir das mãos em direção ao cotovelo. A torneira deve ser fechada com o cotovelo ou por outro profissional, mas não com as mãos. Durante todo o processo, as mãos devem estar sempre acima do nível dos cotovelos. O processo todo deve durar rigorosamente cinco minutos para a primeira cirurgia e três minutos entre dois procedimentos cirúrgicos ${ }^{(1)}$.

\section{A IMPORTÂNCIA DA ATUAÇÃO DO ENFERMEIRO NO CENTRO CIRÚRGICO PARA O CONTROLE DA CONTAMINAÇÃO AMBIENTAL}

Na literatura, o papel do enfermeiro é preconizado em quatro áreas, a saber: administrativa, assistencial, ensino e pesquisa. No papel administrativo, o enfermeiro realiza o planejamento, a organização, a direção e o controle das atividades desenvolvidas nesta unidade. No papel assistencial, elabora um plano de cuidados, utilizando metodologia científica para prestar assistência individualizada e o papel de ensino é relevante porque estimula o enfermeiro a buscar conhecimento para propiciar o aperfeiçoamento da equipe de enfermagem. Como pesquisador, seja individualmente ou em equipe, poderá demonstrar a diferença que existe entre uma assistência que deriva da utilização de conhecimento científico comparada ao cuidado prestado, orientado para o cumprimento de tarefas, normas e rotinas ${ }^{(7)}$.

Em estudo recente, os autores demonstraram a necessidade dos profissionais de saúde que atuam em CC realizarem uma reavaliação das práticas utilizadas para o controle da contaminação ambiental ${ }^{(3)}$. Nesse cenário, ressaltamos a importância da atuação do enfermeiro, pois, enquanto alunas de graduação em enfermagem, entendemos que esse profissional tem papel crucial nesse controle, desenvolvendo atividades que contemplem as quatro áreas de sua atuação, porque é o responsável pelo gerenciamento dessa unidade e deve garantir mecanismos que proporcionem os recursos materiais e humanos necessários. Compete ao enfermeiro promover assistência integral ao cliente, minimizando o medo, a ansiedade e prevenindo as complicações inerentes ao procedimento anestésico cirúrgico. Por meio do ensino, esse profissional deve propor programas educativos periódicos, visando a conscientização da importância da aplicação de medidas para a prevenção da infecção do sítio cirúrgico, para todas as equipes atuantes no $\mathrm{CC}$, as pesquisas desenvolvidas devem contemplar problemas vivenciados no cotidiano e seus resultados evidenciem práticas que possibilitem a melhoria da assistência prestada ao cliente e as condições de trabalho na unidade, bem como a diminuição dos custos hospitalares. 


\section{CONSIDERAÇÕES FINAIS}

O presente texto permitiu abordar aspectos relevantes relativos à paramentação cirúrgica e escovação das mãos que constituem medidas importantes dentro do controle da contaminação ambiental, para a prevenção da infecção do sítio cirúrgico.

Ressaltamos ainda que, para a atuação do enfermeiro ser efetiva neste contexto, esse profissional deve ser o elo entre as equipes médica e de enfermagem e a Comissão de Controle de Infecção Hospitalar da instituição em que trabalha.

\section{REFERÊNCIAS BIBLIOGRÁFICAS}

1. Associação Paulista de Estudos e Controle de Infecção Hospitalar. (SP). Prevenção da infecção de sítio cirúrgico. São Paulo (SP): APECIH; 2001.

2. Graziano KU.Controle da contaminação ambiental da unidade de centro cirúrgico. Enfoque 1994 janeiro; 1(21):1922.

3. Nobre LF, Galvão CM, Graziano KU, Corniani F. Avaliação de indicadores de controle da contaminação ambiental da sala de operação: um estudo piloto. Medicina 2001 abril; 34(2):183-93.

4. Lacerda RA. Fatores de risco relacionados ao ambiente e a limpeza da sala de operação. In: Lacerda RA, organizadora. Buscando compreender a infecção hospitalar no paciente cirúrgico. São Paulo (SP): Atheneu; 1992. p. 116-24.

5. Lacerda RA. Centro Cirúrgico. In: Fernandes AT, Fernandes MOV, Ribeiro N Filho. Infecção hospitalar e suas interfaces na área da saúde. São Paulo (SP): Atheneu; 2000.p. 789818.

6. Lacerda RA. Paramentação cirúrgica: importância no controle de infecção em Centro Cirúrgico. In: Lacerda RA, organizadora. Controle de Infecção em Centro Cirúrgico. Fatos, Mitos e Controvérsias.São Paulo (SP): Atheneu; 2003.p.261-75.

7. Roza IB. O papel do enfermeiro em centro cirúrgico. Rev Gauch Enfermagem 1989 julho; 10(2):20-5. 